Çeviri / Translation

\title{
Farsça İki Tarihî Metinde Efrasiyab'ın Türkçe Adı
}

\author{
Yazan: Seccad AYDINLU* \\ Çeviren: Umut BAŞAR**
}

İranlıların millî kahramanlık anlatılarında, en büyük ve tanınan destansı düşman Efrasiyab olup onun şahsına dair işaretlere; Avesta'da, parça hâlindeki hikâyelerde ve geç dönem şifahi destanlarda rastlanmaktadır (bk. Aydınlu, 1384 c. 1; Razi, 1381, c. 3; Sadikiyan, 1375, cilt 1 ve Yarshater, 1998, vol.1). Bunların tamamının derlenip incelenmesi, müstakil bir kitap veya teze konu olabilecek hacimdedir. Bu konuda bazı ince gönderme ve ifadeler; mevcut şüpheleri dağıtmak, Efrasiyab hakkındaki ve son tahlilde İran kahramanlık destanlarındaki belirsizlikleri aydınlatmak adına daha fazla dikkat ve açıklama (bk. (Aydınlu, 1396 ve Tefezzuli, 1398) gerektirmektedir. Bu noktada gözden kaçan hususlardan biri Efrasiyab'1n, Muhammed Gazali'nin (ö. 1111) Nasihatü'l-mülük ve Necmeddin Daye'nin (ö. 1256, er Razi) Mermuzat-ı Esedi der Mezmurat-ı Davudi adlı eserlerindeki Türkçe adıdır.

Gazali, Nasihatü'l-mülük'ü ömrünün sonlarına doğru hicri kameri 500-503 (miladi 1106/07-1109/10) yıllarında kaleme almıştır. Kitabın ilk bölümü "İman” hakkındadır. İkinci bölüm ise "Adalet, Siyaset, Padişahların Adetleri, Vezirlerin Adetleri, Kâtiplerin Zikri, Hükümdarların Gayreti, Kadınların Nitelikleri” olmak üzere yedi başlık şeklinde düzenlenmiştir (bk. Saket, 1397). Eserin ilk tashihli neşri, Celaleddin Homayi tarafından Et'teberü'l-mesbuk fi nasitü'l-mülük isim-

\footnotetext{
* Yayımlandığı Yer: Fars Dil Kurumu, Name-yi Ferhengistan, yıl 17-Kış, sayı 2, sayfa 65-72.

** Doç. Dr, Urmiye Peyamı Nur Üniversitesi Öğretim Üyesi.

*** Dr., Ankara Sosyal Bilimler Üniversitesi, Yabancı Diller Yüksek Okulu, Ankara, Türkiye.

Elmek: umutbasar_35@hotmail.com

https://orcid.org/0000-0001-5571-7103.
} 
li Arapça tercümeye de bakarak şemsi 1315-1317 (miladi 1936-1938) yıllarında yayınlanmıştır. Eserin ikinci bölümünde yer alan "Padişahların Âdetleri” başlıklı kısımda İran hükümdarlarının isimleri ve saltanat yıllarının anlatıldığı yerde, bazı araştırmacıların Gazali’ye ait olup olmadığında tereddütte düştükleri şu ibare geçmektedir:

“... ve ondan sonra ... Efrasiyab oldu [tahta geçti] ki Türkler ona Eltoka Alb Ar [التكا الب آر] ' derlerdi ve aslan misali bir yiğit olup dünyayı titretirdi ve İran'daki saltanatı on iki yıl sürdü (Gazali, 1315-1315: 43)."

Üstat Homayi, Nasihatü'l-mülük'ün daha sonra metnin yedi el yazma nüshası ve üç Arapça tercümesine bakarak yeniden tashihli neşrini yapmış, bu neşrin ilk baskısı şemsi 1351 (miladi 1972) yılında çıkmıştır. Efrasiyab'a Türklerin atfettiği isim bu yayında değişikliğe uğramıştır:

“... ve ondan sonra Efrasiyab geldi ve İran'ı aldı ve Türkler ona Konka Alb [كنكا الب] derlerdi” (Gazali, 1368: 91).

Et'teberü'l-mesbuk fi nasitü'l-mülük ismiyle hicri kameri 1429 (miladi 2007) yılında Heysem Halifetü't-taimi tarafindan hazırlanarak Beyrut'ta basılan Arapça tercümede, Efrasiyab'a ve onun Türkçe adına ilişkin herhangi bir cümle yer almamaktadır. ${ }^{2}$

Gazali'den yaklaşık 120 yıl sonra Necmeddin Daye Mermuzat-1 Esedi der Mezmurat-1 Davudi adlı kitabını hicri 621'de (miladi 1199) Erzincan'da kaleme almıştır. Bu kitapta ise on alegorik öge yer almaktadır ki irfani meseleler, ülke yönetime dair konular, adalet ve müellifin dönemine değin hükümdar ve halifelerin tarihi anlatılmıştır (bk. Necmeddin Razi, 1381: 21-22, musahhinin önsözü). Necmeddin Daye "Âdem Aleyh Selamdan [Günümüze] Hükümdarların Tarihi” başlığını taşıyan bölümde aşağıdaki gibi yazmaktadır:

“... ve ondan sonraki Efrasiyab’tı ve Türkler ona Konkalb [كنكالب] derlerdi ve onun İran'daki saltanatı on iki y1l sürdü, aslan misali bir yiğit olup dünyayı titretirdi (aynı eser, 108-109)."

Şefii Kedkeni’nin (aynı eser, 209) dikkat çektiği üzere Mermuzat-l

1 Metindeki soru işareti doğrudan metni yayına hazırlayan araştırmacıya aittir (mütercim).

2 Anlaşılan o ki Gazali'nin eserini Arapçaya tercüme eden mütercim ilgili bölümü bilerek veya bilmeyerek atlamıştır (mütercim). 
Esedi’nin “Acem Hükümdarları Tarihli” başlıklı kısımları lafız, ibare ve içerik açısından Nasihatü'l-mülük'teki aynı bölümle oldukça benzeşmektedir. Dolay1sıyla ya Nasihatü'l-mülük'ten özetlenerek alınmıştır ya da Gazali ve Necmeddin Daye, aynı olan daha eski bir kaynağı kullanmıştır.

Efrasiyab'ın lakabına dair Nasihatü'l-mülük'ün birinci ve ikinci tashihinde ve sonra Mermuzat-1 Esedi' de geçen üç farklı imla incelendiğinde akla iki soru gelmektedir. Öncelikle "Eltoka Alb Ar", "Konka Alb” ve "Konkalb" isimlerinden hangisini Türkler Efrasiyab için kullanmaktaydı? İkinci olarak ise bu Türkçe ismin anlamı nedir?

Orta Asya'daki Türklerin eski kahramanlık destanlarında Efrasiyab'ın adı Alp Er Tunga [آلب ار تونقا] veyahut Tunga Alb Er [آبكا الب ار)] şeklinde geçmektedir. Bu isim, üç Türkçe kelimeden müteşekkildir. Alp (kahraman, cesur), er (erkek) ve tunga (kaplan) (bk. Kaşgarlı, 1375: 94-216-528). Bu doğrultuda Alp Er Tunga/ Tunga Alp Er, kaplan gibi cesur adam anlamındadır (aynı eser: 527).

Yukarıda bahsedilen iki tashih ve bir esere, Tunga Alp Er adının tahrif olarak girdiği anlaşılmaktadır. Zira "Eltoka Alb Ar" yazımında "Tunga", "Eltoka'ya" ve "Er" ise "Ar'a” dönüşmüştür. "Konka Alb" ve "Konkalb” yazımlarında ise gene "Tunga" kelimesi "Konka'ya” evirildiği gibi "Er" kelimesi düşmüş, Mermuzat-l Esedi' de "Alb” kelimesi "Leb'e" dönüşmüştür.

Görüldüğü kadarıyla bu Türk kahramanının adının İran destanlarındaki Efrasiyab'la özdeşleştirilerek “Alp Er Tunga” şeklinde geçtiği ilk kaynak Kutadgu Bilig'dir. Maveraünnehr'de Kaşgar yakınlarında, Balasagunlu Yusuf Has Hacip tarafından hicri 462 (miladi 1069-1070) yılında Türkçe kaleme alınan bu 6645 beyitlik bu eser, feulün feulün feulün feul vezninde hazırlanmıştır. Bu manzumede aşağıdaki ibareler geçmektedir:

"Bu Türk beyleri arasında Alp Er Tunga namında meşhur biri vardı ki bahtı açıktı. Bilgin ve hünerli bir adamdı. İlim ve idraki sayesinde halkın nezdinde itibarlı biriydi. Hem seçkin hem yüce hem de cesur bir adamdı. Dünyada sadece feraset sahipleri hükümdar olabilirler. İranlılar ona Efrasiyab derdi. Efrasiyab birçok ülke fethetmişti. Dünyayı almak için ilim ve idrak gereklidir. İranlılar onu kitaplarında yazmışlardır. Eğer kitaplar olmasaydı onu kim tanırdı?” (Has Hacip 1394, 176). 
Kutadgu Bilig'den birkaç yıl sonra Kaşgarlı Mahmut hicri 474-476 (miladi 1072-1074) yazdığı Divanu Lügati't-Türk’te, söz konusu ismi Tunga Alb Er [تئ şeklinde kaydetmiş ve anlamını “Büyük Türk Hükümdarı Efrasiyab’ın lakabı” diye vermiştir (Kaşgari, 1375: 528). Ayrıca başka bir yerde onun ölümü sebebiyle yazılan birkaç kıtayı aktarmıştır.

Aynı metinde onun Bijen'in de hapsedildiği "Berçuk" [برجق] ile Merv [مرو] şehirlerini inşa ettiğgi, "Bersagan” [برسغان], “Barman” [بارمان] ve "Kaz"3 [قان] isimlerinde iki oğlu ve bir kızı olduğu belirtilmektedir (Kaşgari, 1375: 318-323727-1087). İki defa açıklanan “Kaz” madde başında babası olan Tunga Alb Er'in Efrasiyab olduğu verilmektedir (aynı eser, 1375: 737).

Bu iki metin dışında, Oğuz Türkçesiyle kaleme alınmış bir epik manzume olan Yel-i Gulasa'nın [يلى غول آسا] bazı bölümlerinde Alp Er Tunga'nın oğlu olan “Alp Arız” [آلب آريز] ismine tesadüf edilmektedir. Manzumeye göre Alp Arı, öyle uzun boyludur ki onun ipek elbisesinden doksan kadar adama giyecek dikilebilir (bk. Serkarati, 1378: 281 ve Yarshater, 1998: 576). Türk kahramanı Alp Er Tunga'ya ilişkin tarafımızdan bulunabilen işaretler, görüldüğü üzere dağınık ve sınırlı sayıdadır. Lakin dikkatle düşünüldüğünde onun şahsına dair göndermelerin büyük ihtimalle daha fazla olduğu ancak Türklerdeki şifahi gelenek ${ }^{4}$ sebebiyle zaman içerisinde unutulduğu ya da keşfedilmeyi beklediği tahmin edilebilir.

İran millî destancılık geleneğinde asli düşman doğu ve kuzeydoğudan İran topraklarına akınlar düzenleyen Turan ülkesinin sakinleri olan Turanlılardır. Gerçekten de tarihî süreçte özellikle de Sasaniler Dönemi’nde (226-651) İranlıların doğu komşusu olan Türk kavimleri, tam da Turanlıların İran destanlarında saldırdığı bölgeden İran’a akınlar düzenlemiştir. Türklerin doğu ve kuzeydoğudan İran’a, destan anlatı geleneğindeki Turanlıları anımsatacak şekilde uzun soluklu akınları, yavaş yavaş İran'ın doğu sınırındaki destani ve tarihî düşmanın birleşmesine yol açmıştır. Dahası destanlardaki "Turânî”, "Turân” kelimeleriyle gerçek tarihteki "Türk / Türkân”, "Türkistân” kelimeleri birbirinin muadiline dö-

3 Divanu Lügati t-Türk’ün iki yerinde (Kaşgari, 1375: 737 ve 1087) Kaz, Siyavuş’un eşi olarak tanıtılmaktadır ki dolayısıyla Kaz'ın Şahname ve diğer İran destanlarında geçen Efrasiyab'ın kızı Ferengis'le aynı şahıs olduğu anlaşılmaktadır.

4 Kutadgu Bilig gibi edebî eserlerde Alp Er Tunga'dan bahsedilmesi, İranlıların onu yazıya geçirmemiş olsaydı Türklerin ondan haberdar olmayacağını ve destan geleneğinin Türkler arasında şifahi olduğunu göstermektedir. 
nüşmüştür. ${ }^{5} \mathrm{Bu}$ birleşimin Sasaniler Dönemi eseri olan Hodayname’ye uzandığ 1 anlaşılmaktadır. Firdevsi'nin Şahname'yi kaleme alırken bu eseri kaynak olarak kullanması sebebiyle kitabında defalarca Efrasiyab ve Turaniler, Türk olarak addedilmiştir. Bir misal aşağıda yer almaktadır:

'O Türk (Efrasiyab) cenkte erkek ejderhaya benzer,

Nefesi ateş, kindarlıkta ise bela bulutu gibidir (Firdevsi, 1393: cilt 1, beyit 25).”

Ne var ki bazı müverrih ve müellifler hatta Firdevsi Şahname’yi tamamlamadan önce Efrasiyab'ın Türk olmadığına dikkat çekmiştir. Örneğin Mesudi, Mürevvicü'z-zeheb'de (hicri 332/miladi 943-944) şöyle yazmaktadır:

“Tarihçilerin hataya düşerek onu Türk zannetmesinin sebebi Efrasiyab’ın doğduğu yerin Türk diyarı olmasından kaynaklanmaktadır” (Mesudi, 1387, cilt 1:221).

Bu duruma rağmen kaynağını Şahname'den alan anlatılar sayesinde Efrasiyab ve Turanlıların Türk olarak tanınması gerek Fars Edebiyatı'nda gerekse de İran tarih yazımında Efrasiyab'ın bir Türk kahramanı olarak telakki edilmesine sebep olmuştur. Öyle ki Çiğil Türklerinden gelen Karahanlılar soyunu Efrasiyab’a dayandırarak kendilerini "Âl-i Efrasiyab" şeklinde isimlendirmişlerdir (bk. Paketçi, 1393, 2; Serkarati, 1383, cilt 8: 458 ve Mecmelü't-tevarih vel-Kısas, 1383: 408). Hoca Nizamülmülk Tusi de Selçukluların “Büyük Efrasiyab’ın” nesebinden geldiğini kaydetmiştir (Nizamülmülk Tusi, 1398: 13). Cüneyni’nin Cihanguşa'sında da Uygur Hükümdarı Bökü Han [بوقو خان] da Efrasiyab'a bağlanmaktadır (Cüveyni, 1388, cilt 1:38).

Efrasiyab, İran destan anlatılarında genellikle çok tanınan güçlü bir kahraman olması nedeniyle İran' daki Türk hanedanlarının dikkatini çekmiştir. Muhtemelen Orta Asya Türkleri de Efrasiyab ve onun kahramanlıklarıyla tanıştıktan sonra, kendi destansı figürleri olan Alper Tunga'yla onu -ki bana göre her ikisi farklı ve müstakil şahsiyetlerdir- birleştirmişlerdir. Böylelikle bu iki Türk yiğidinin aslında bir şahıs, Farsça adının Efrasiyab Türkçesinin ise Alper Tunga olduğu kabul edilmiştir.

Konuya dair eldeki en eski yazılı kaynak şimdilik hicri beşinci yüzyılın ikinci yarısına uzansa da büyük ihtimalle bu iki şahsiyetin Türk şifahi destan ge- 
leneğinde birleştirilmesi hicri beşinci yüzyıldan önce olmuştur. Nitekim Gazali de hicri altıncı yüzyılın başlarında bu Türk cengâverinin adını, en azından hicri beşinci yüzyıla ait olması beklenen Arapça veyahut Farsça kaynaklara dayanarak Efrasiyab'a nispet ederek aktarmıştır. Bu ise Alp Er Tunga isminin ve onun Efrasiyab olduğuna dair düşüncenin en azından bu yüzyılda (hicri beşinci) İran kronikleri ve anlatılarına -her ne kadar Nasihatü'l-mülük ve Mermuzat-ı Esedi dışında başka bir eserde henüz rastlanmasa da- girdiğini ortaya koymaktadır.

Farsça bu iki metin içerisinde, Nasihatü 'l-mülük'ün ilk tashihinde yer alan “Eltoka Alb Ar" [التكا الب آر] imlas1, Tunga Alb Er [تنكا الب ار] ismine en yakın olan kayittır. Ancak bu tashihin hicri 1267/miladi 1850-1851'de kitabet edilen geç bir nüshaya dayandığı göz önünde bulundurulduğunda, bu kaydın kelimenin asli imlası olmadığı, muhtemelen kâtibin tasarrufuyla söz konusu biçimde yazıldığı düşünülebilir. Bu yüzden eserin daha eski el yazma nüshalarına dayanan ikinci tashihindeki "Konka Alp" [كنكا الب] imlası Gazali'ye aittir ve görünüşe göre Necmeddin Daye ise eserini telif ederken kullandığı kaynaklarda bu ismi "Konkalp" [كنكالب] şeklinde görmüş veya okumuştur.

Yöntem açısından bu iki imlanın tashihinin, yazma eserleri tashih edenlerin kullandığı tekniğin bir ürünü olduğunu ve Türk hükümdarı "Tunga Alb Er'in" adının doğru kaydıyla mukayese etmek gerekmediği bilinmelidir. Çünkü ilmi tashihten nihai hedef, müellif ve şairlerin yanlış ya da bozulmuş kayıtlarını da tespit edebilmektir. Bu konuda da mevcut el yazmalarına bakıldığında Gazali ve Necmeddin Daye, "Tunga Alb Er" [نكا الب ار] adını tahrif olmuş bir

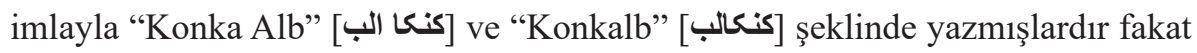

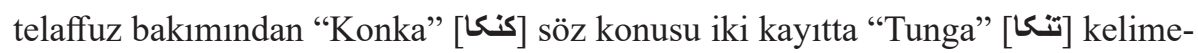
sinin tahrif olmuş şekli olduğundan hem Nasihatü'l-mülük hem de Mermuzatı Esedi' de şüpheye yer vermeyecek bir şekilde kef [S] harfi zammeyle okunmalıdır. Zira kaplan manasına gelen ve Nasihatü'l-mülük ile Mermuzat-ı Esedi' de "Eltoka" [كنكا] [نتكا] șekline evirilen "Tunga" [تنكا], Divanu Lügati t-

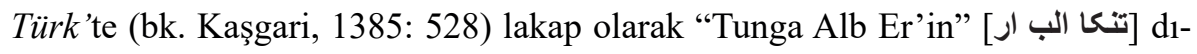
şında, “Tunga Han” [تنكا خان], “Tunga Tekin” [تكحا تكين] vb. şekilde birçok defa kullanılmıştır. 


\section{Kaynaklar $^{6}$}

Aydınlu, Seccad (1384), "Efrasiyab", Danişnameyi Zeban u Edeb Farsi, be Serperestiyi İsmail Saadet, cilt 1, Tahran: Ferhengistanı Zeban u Edebi Farsi, s. 473-477.

Aydınlu, Seccad (1394), Defteri Hosravan (Bergozideyi Şahnameyi Firdovsi), Tahran: Suhan.

Aydınlu, Seccad (1396), "Bazşinasiyi Rivayeti Ekvan Div der Sünneti Destaniyi İran”, Nimpohte Torenç (Bist Makale Derbareyi Şahname ve Edebi Hamasiyi İran), Tahran: Sohan, s. 312-313.

Cüveyni, Ata Melik (1388), Tarihi Cihanguşayı Cüveyni, be Tahsih ve Talikatı Habibullah Abbasi ve İreç Mohreki, cilt 1, Tahran: Zevvar.

el-Gazzali, Muhammed (h. 1429), Et'teberü'l-mesbuk fi nasitü'l-mülük, be ihtimamı Heysem Halifetü’t-taimi, Beyrut: el-Mektebe el-Talimiyye.

Firdevsi, Ebulkasım (1393), Şahname, Pirayeşi Celal Haliki Mutlak, Tahran: Suhan.

Gazali, Muhammed (1315-1317), Nasihatü'l-mülük, be Tashihi Celalettin Homayi, Tahran: Çaphaneyi Meclis.

Gazali, Muhammed. (1368), Nasihatü'l-mülük, be Tashihi Celalettin Homayi, Tahran: Homa.

Has Hacib (Balasagunlu), Yusuf (1394), Kutadgu Bilig, Mukaddime, Tedvin ve Tercüme Muhammed Kerimi, Tebriz: Ahter.

Hoca Nizamülmülk Tusi (1398), Seyrü'l-mülük (Siyasetname), be Tashih ve Talikatı Mahmut Gubafi, Tahran: Ferhengistanı Zeban u Edebi Farsi.

Kaşgari, Mahmud bin Hüseyin (1357), Divanu Lügati 't-Türk, Tercüme ve Tanzim Seyit Muhammed Debir Siyaki, Tahran: Pejuheşgahı Ulumu İnsani ve Mutaalatı Ferhengi.

Kaşgari, Mahmud bin Hüseyin (1384), Divanu Lügati t-Türk, Tercüme Hüseyin Muhammedzade Slddık, Tebriz: Ahter.

Mecmelü't-tevarih vel-Kısas (1383), be Tashihi Melikü'ş-şuara Bahar, Tahran: Dünyayı Kitab.

Mesudi, Ebulhasan (1387), Mürevvicü'z-zeheb, Tercüme Ebulkasım Payende, cilt 1, Tahran: İm u Ferhengi.

Necmeddin Razi (1381), Mermuzat-ı Esedi der Mezmurat-ı Davudi, be Tashihi ve Talikatı Muhammed Riza Şefii Kedkeni, Virayeş 2, Tahran: Suhan.

Paketçi, Ahmed (1393), "İlhaniyan”, Tarihi Camiyi Iran, Ziri Nazarı Kazım Musevi Bocnurdi, cilt 7, Servirestar Doktor Sadık Seccadi, Tahran: Merkezi Dairetül Maarifi Bozorgu İslami, s. 165.

Razi, Haşim (1381), Danişnameyi Iranı Bastan, Cilt 3, Tahran: Suhan, s. 1520-1530.

6 Makalede yazarın, bazı Türkçe kaynakların İran baskısını kullandığı anlaşılmaktadır. Öte yandan çalışmanın kaynakçası makalenin özgün hâlinde verildiği şeklinde aktarılmış olup herhangi değiştirme ve düzenlemeye gidilmemiştir (mütercim). 
Sadıkiyan, Meyhindust (1375), Ferhengi Esatiri ve Hamasiyi İran, cilt 1, Tahran: Pejuheşgahı Ulumu İnsani ve Mutaalatı Ferhengi, s. 313-330.

Saket, Selman (1397), “Nasihatü'l-mülük”, Danişnameyi Zeban u Edebi Farsi, be Serperestiyi İsmail Saadet, Tahran: Ferhengistanı Zeban u Edebi Farsi, s. 556-559.

Serkarati, Behmen (1387), “Bakayayı Efsaneyi Gerşasb der Manzumeyi Hamasiyi İran”, Sayehayi Şikarşode, Tahran: Katre, s. 250-276.

Serkati, Behmen (1383), “Turan”, Danişnameyi Cihanı Íslam, cilt 8, Tahran: Merkezi Dairetül Maarifi Bozorgu İslami, s. 356-357.

Tefezzuli, Ahmed (1398), "Hastegarı Efrasiyab ez Espendarmed”, Makalatı Ahmet Tefezzuli, be Kuşeşi Jale Amuzgar, Tahran: Tus, s. 238-251.

Yarshater, Ehsan (1998), “Afrasiyab”, Encylopaedia Iranica, Edited by Ehsan Yarshater, vol 1, New York, p. 584-593. 